\title{
Effects of aqueous extract of Neem (Azadirachta indica) leaves as growth promoter and anti-colibacillosis in broilers
}

\author{
SK Sarker, M Mostofa*, F Akter, MM Rahman, MR Sultana
}

Department of Pharmacology, Faculty of Veterinary Science, Bangladesh Agricultural University, Mymensingh 2202; Bangladesh

\begin{abstract}
The study was conducted to determine the efficacy of aqueous extract of Neem leaves against colibacillosis and as a growth promoter in broilers. A total of 40 commercial day-old broiler chicks were randomly divided into four equal groups; viz. A, B, C and D. Group A was kept as non-treated control, Group B and C was treated with $1 \%$ Neem leaves in drinking water for six weeks, and colibacillosis was induced at $2^{\text {nd }}$ week in group $C$ and $D$. In group $D$, Neem leaves treatment continued from $2^{\text {nd }}$ to $6^{\text {th }}$ week after the colibacillosis induction to compare its antibacterial efficacy to prophylactic effect. Escherichia coli induction rate was $200 \mu \mathrm{l}$ per bird where $1 \mathrm{ml}$ contains approximately 1 X $10^{6}$ CFU (Colony Forming Unit). Data were recorded for live body weight, weekly gain in weight and hematological parameters of birds for six weeks. Clinical examination and antibacterial sensitivity studies suggests administration of aqueous extract of Neem leaves significantly $(p<0.001)$ improved body weight gain in the Neem treated groups but did not prevent E. coli induced colibacillosis in broilers.
\end{abstract}

Key words: antibacterial sensitivity test, Azadirachta indica, colibacillosis, Neem leaves extract

Bangladesh Animal Husbandry Association. All rights reserved. Bang. J. Anim. Sci. 2014.43 (2): 138-141

\section{I ntroduction}

Many synthetic drugs and growth promoters are supplemented to the broilers to effect rapid growth, but there use have shown many disadvantages like high cost, adverse side effect on health of birds and long residual properties (Nayaka et al. 2012). Exploring new antibiotics from the medicinal plants is a priority is this era of antibiotic resistance to increase the production of broilers. Various plant extracts have been used worldwide for a range of medicinal properties like antibacterial, antiviral, antifungal, antiprotozoal and hepatoprotective without adverse effects (Kale et al., 2003). One of the alternatives could be the leaves extract of Azadirachta indica.

Indigenous uses of $A$. indica (common name in Hindi is 'Neem') leaves in different parts of India for curing gastrointestinal disorder such as diarrhea and cholera is wide spread (Thakurta et al. 2007). The medicinal property of Neem leaves in ayurvedic system of medicine is well recognized in Bangladesh, India and Pakistan.
In general, Neem leaves extract may be used therapeutically to control respiratory problems, constipation and also as health promoter (Biswas et al. 2002). Aqueous extract of Neem leaves extract has a good therapeutic potential as anti-hyperglycemic agent, antibacterial agent and could be used for controlling airborne bacterial contamination in the residential premise (Mishra et al. 2013).

It was shown that Neem leaves extract acts as a growth promoter (Landy et. al. 2011), improve performance and hematological parameters (Nayaka et. al. 2013) and immune response (Nayaka et. al. 2012; Jawad et. al. 2013) in broilers. However, no data is available about the combined effect as growth promoter and anticolibacillosis in broilers. Therefore, the objectives was to investigate the growth performance of broilers supplemented with Neem leaves extract and to examine the effects of aqueous extract of Neem leaves against colibacillosis in broiler chicken. 


\section{Materials and Methods}

Neem leaves powder was prepared by sun drying the leaves for 10 days followed by oven at 55$60^{\circ} \mathrm{C}$ for 2 days (Jawad et al. 2013). After pulverizing with a blender, fine dust was obtained by sieving with 25 unit mesh diameter sieve. $10 \mathrm{~g}$ of Neem leaves powder was added to 1 Liter of distilled water and boiled. Finally the solution was filtered and supernatant was taken to make $1 \%$ extract. Extracts were stored at $4{ }^{\circ} \mathrm{C}$ temperature in refrigerator for antimicrobial studies.

Forty (40) commercial broiler day-old chicks were collected from Nourish Poultry and Hatchery Limited, Gazipur. The birds were kept on a floor litter system, each group in separate pens measuring $0.9 \times 1.2$ meters. The pens were thoroughly cleaned, white-washed and disinfected before use. Chicks were acclimatized for 7 days in the experimental shed and brooded at $35^{\circ} \mathrm{C}$ during first week and the temperature was reduced by $3^{\circ} \mathrm{C}$ every week until the temperature reached room temperature at $25 \pm 1^{\circ} \mathrm{C}$. All the groups were reared under the similar conditions of temperature, humidity, light, ventilation and floor space throughout the experimental period. Birds were fed commercial feed from Nourish Poultry Feed Limited and water ad libitum under strict bio-security (Molla et al. 2012).

All the 40 chicks were randomly divided into 4 equal groups of 10 birds in each group ( $A, B, C$ and $D$ ). Group ' $A$ ' was kept as control without any treatment, group ' $B$ ' and ' $C$ ' were treated with $1 \%$ Neem leaves in drinking water for consecutive six weeks. Chickens of group ' $C$ ' were given E. coli orally at $2^{\text {nd }}$ week of age @ $200 \mu \mathrm{l} /$ bird, where $1 \times 10^{6} \mathrm{CFU}$ (Colony Forming Unit)/ $1 \mathrm{ml}$ (Arenas et al. 1999) to study the prophylactic effect of the Neem leaves in the induction of colibacillosis and group ' $D$ ' was challenged with same amount of $E$. coli at $2^{\text {nd }}$ week followed by immediate treatment with $1 \%$ Neem leaves in drinking water from $2^{\text {nd }}$ to $6^{\text {th }}$ week. Control and treated groups were closely observed for six weeks (42 days).

The effect of aqueous extract of Neem leaves on body weight of broilers was recorded. Broilers under treatment and control groups were weighed with electric weighing machine. The weight of each broiler was taken before feeding in the morning at a weekly interval. Mean live weight gain of each group of broilers on $7^{\text {th }}, 14^{\text {th }}$, $21^{\text {st }}, 28^{\text {th }}, 35^{\text {th }}$ and $42^{\text {nd }}$ days was recorded.

At the end of the experiment $\left(42^{\text {nd }}\right.$ day) blood samples were collected from wing vein in both control and treated groups. Hematological parameters like; total erythrocyte count (TEC) by Hayem's solution (Lamberg and Rothstein 1978), packed cell volume (PCV) by microhaematocrit method (Hutchison 1960), hemoglobin concentration by Sahli's acid hematin method (Brown 1976) and erythrocyte sedimentation rate (ESR) by the Wintrobe hematocrit method (Westergren 1957) were determined.

The microorganism in the present study was: $\mathrm{Gm}$ (-ve) - E. coli. All the cultures were collected from Department of Microbiology and Hygiene, Faculty of veterinary Science, Bangladesh Agricultural University, Mymensingh. Zone of inhibition was determined by disc diffusion method (Bauer et al. 1966). In brief, Muller hinton agar (Hi MediaM173-500G) was prepared in the plates as the media for test organisms. Sterile whatmann No. 1 filter paper was used to prepare discs of $6 \mathrm{~mm}$ in diameter. The cultures were diluted to a density equivalent to the $1 \%$ barium sulfate standard to obtain suspension containing approximately $1 \times 10^{6} \mathrm{CFU} / \mathrm{ml}$. A $0.1 \mathrm{ml}$ of each microbial suspension was spread evenly onto the surface of the agar plates using sterile glass spreader. After the inoculation of culture the sterile disc were carefully loaded with $20 \mu$ l of $1 \%$ Neem leaves and placed onto the agar plates. All the plates were incubated at $37^{\circ} \mathrm{C}$ for 48 hours.

All data were expressed as mean \pm SEM and differences among the groups of birds were compared using one-way ANOVA. Statistical significance was set at $p<0.05$. Statistical analysis was performed using SPSS software version 17 (SPSS Inc., Chicago, IL, USA).

\section{Results and Discussion}

Effects of the aqueous extract of Neem leaves on body weight of broiler are presented in Figure 1. Broilers supplemented with $1 \%$ Neem leaves extract (group B, C and D) gained the significantly higher $(p<0.001)$ live weight

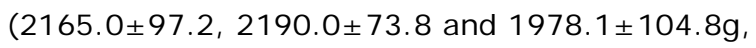
respectively) compared to untreated control 


\section{Aqueous extract of Neem leaves in broiler diet}

regardless of colibacillosis induction (Figure 1 ). During $1^{\text {st }}$ and $2^{\text {nd }}$ week Neem leaves extract did not show any effect on body weight gain. However, from $3^{\text {rd }}$ to $6^{\text {th }}$ week Neem leaves extract significantly increased the body weight of broilers. It could be due to the minimum time necessary for the Neem leaves extract to influence the body weight positively. Birds supplemented with Neem leaves extract had higher body weight and weekly gain in weight. These results may be due to antimicrobial and anti-protozoal properties (Kale et al. 2003, Bishnu et al. 2009) of Neem leaves, which help to reduce the microbial load of birds.

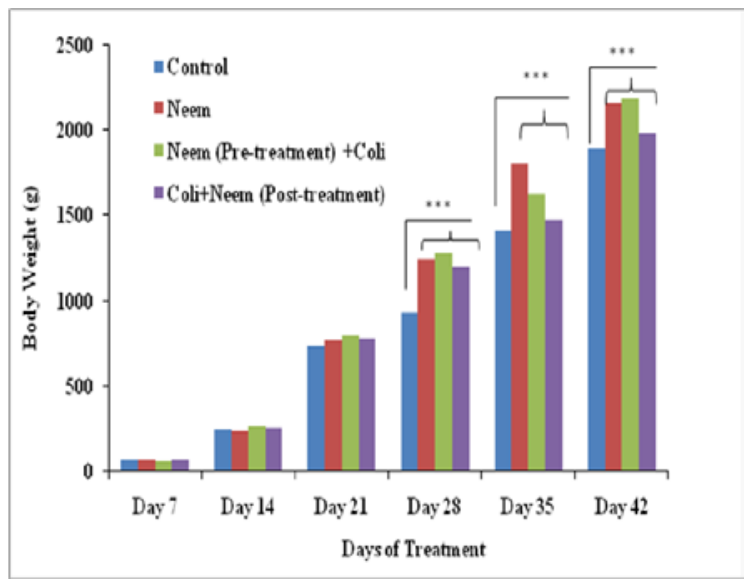

Figure 1. Effects of Neem on body weight (g) in control and treated broilers (Results are expressed as mean value $(n=10$ samples per group); ***, $\mathrm{p}<0.001$; significant with the control (A) and all treated groups)

Effects of Neem leaf extract on hematological parameters are summarized in Table 1 . The Neem leaves treatment has significantly changed some of the hematological parameters, i.e. TEC, PCV and ESR in Neem treated groups (Table 1). Neem+colibacillosis group showed significant $(p<0.05)$ increase $(2.83 \pm 0.03$ million $/ \mu l)$ in TEC in comparison to control group. However, there was no significant increase in the $\mathrm{Hb}$ content in any group. Contrary to the present findings, Biu et al. (2009) opined that inclusion of Neem in broilers significantly decreases hemoglobin concentrations. In our study PCV values significantly $(p<0.01)$ increased in Neem control group which is similar with the finding of Nayaka et al. (2013). These results suggest that aqueous Neem leaves treatment may alter some of the hematological parameters (Table 1 ).
Table 1: Comparison of the Neem leaves treatment on hematological parameters in different treated groups

\begin{tabular}{lcccc}
\hline \multirow{2}{*}{ Groups } & \multicolumn{4}{c}{ Mean \pm SEM } \\
\cline { 2 - 5 } & $\begin{array}{c}\text { TEC } \\
\text { (million/ } / \mathrm{l})\end{array}$ & $\mathrm{Hb}(\mathrm{g} \%)$ & PCV\% & $\begin{array}{c}\text { ESR (mm } \\
\text { in } 1 \text { st } h)\end{array}$ \\
\hline A & $2.81 \pm 0.05$ & $7.55 \pm 0.2$ & $20.00 \pm 0.6$ & $5.50 \pm 0.6$ \\
B & $3.09 \pm 0.06^{* * *}$ & $7.90 \pm 0.2$ & $24.50 \pm 0.9^{* *}$ & $3.25 \pm 0.2^{*}$ \\
C+CBS & $2.83 \pm 0.03^{*}$ & $7.60 \pm 0.08$ & $19.50 \pm 0.5$ & $6.75 \pm 0.8$ \\
D+CBS & $2.90 \pm 0.02$ & $7.65 \pm 0.09$ & $20.75 \pm 0.6$ & $4.50 \pm 0.8$ \\
\hline
\end{tabular}

A, control; B, Neem control; C, Pre-treatment with Neem, CBS, Colibacillosis; D, Post-treatment with Neem; significant with the control $(A)$ and all treated groups $(*, \mathrm{p}<0.05, * *, \mathrm{p}<0.01 ; * * *, \mathrm{p}<0.001)$

Antibiotic sensitivity test was performed using $1 \%$ aqueous extract of Neem leaves by Agar Well Diffusion Technique but the extract did not show any activity on E. coli. It might be due to aqueous extract of Neem leaves which was tested in this study. Aqueous extract was found to have less antimicrobial activity whereas Mishra et al. (2013) suggested that methanolic extract of Neem leaves showed $2.4 \mathrm{~cm}$ zone of inhibition at $1.5 \%$ concentration. Previous studies have also showed that leaves extracts of A. indica were found effective against $\mathrm{E}$. coli and $\mathrm{S}$. faecalis with fairly high degree of sensitivity $(I Z=18-33 \mathrm{~mm})$ to methanol extracts (Koona et al. 2011). The antibacterial activity of Neem might be due to presence of triterpenoids, phenolic compounds, carotenoids, steroids, valavinoids, ketones and tetra-triterpenoids azadirachtin (Almas 1999). However, these compounds probably were not extracted in aqueous extract of Neem leaves.

\section{Conclusion}

It can be concluded that supplementation with $1 \%$ aqueous extract of Neem leaves in drinking water cause significant increase in live body weight and improvement in weekly weight gain in broilers as compared to control group. Therefore, $1 \%$ aqueous extract of Neem leaves could use as a growth promoter in broiler industry. Moreover, exploring the possibility to use this extract as growth promoter in other livestock should be priorities and deserve further research. However, aqueous extract of $1 \%$ Neem leaves did not show any indication of antimicrobial activity against $\mathrm{E}$. coli in broilers in this experiment. 


\section{Acknowledgements}

The authors are thankful to Nourish Poultry and Hatchery Ltd, Gazipur for supplying day-old chicks. Authors are grateful to Dr Jayedul Hassan, Assistant Professor, Department of Microbiology and Hygiene for his help in colibacillosis induction and sensitivity test and to $\mathrm{Dr}$ Md Mahmudul Hasan Sikder, Associate Professor, Department of Pharmacology for his great contribution in writing the manuscript. This work was supported by the National Science and Technology funded by the Ministry of Science and Technology, Bangladesh.

\section{References}

Almas K (1999). The antimicrobial effects of extracts Azadirachta indica (Neem). Indian J ournal of Dental Research, 10: 23-26.

Arenas A, Vicente S, Luque I, C. GomezVillamandos JC, Astorga R, Maldonado A, Tarradas C (1999). Outbreak of Septicaemic Colibacillosis in Japanese Quail (Coturnix coturnix japonica). Journal of Veterinary Medicine, 46: 399-404.

Bauer AW, Kirby WM, Sherris JC, Turck M (1966). Antibiotic susceptibility testing by a standardized single disk method. American J ournal of Clinical Pathology, 45: 493-496.

Bishnu J, Sunil L, Anuja S (2009). Antibacterial Property of Different Medicinal Plants: Azadirachta indica, Cinnamomum zeylanicum, Xanthoxylum armatum and Origanum majorana, kathmandu university. J ournal of Science, Engineering and Technology, 5: 143- 150.

Biswas K, Chattopadhyay I, Banerjee RK and Bandyopadhyay U (2002). Biological activities and medicinal properties of Neem (Azadirachta indica). Current Science, 82: 1336-1345.

Biu AA, Yusufu D, Rabo JS (2009). Studies on the effects of aqueous leaf extracts of Neem (A.indica, A. juss) on haematological parameters in chick. African Scientist, 10: 189- 192.

Brown BA (1976). Haematology: Principles and Procedures, 2nd edn. Lea and Febiger, Philadelphia, P. 56-81.

Hutchison HE (1960). On determining the packed cell volume. Journal of Clinical Pathology, 13: 529.

Jawad Z, Younus M, Rehman MU, Maqbool A, Munir R, Muhammad K, Korejo RA, Qazi IH (2013). Effect of Neem leaves (Azadirachta indica) on immunity of commercial broilers against new castle disease and infectious bursal disease. African Journal of Agricultural Research, 8: 4596-4603.

Kale BP, Kothekar MA, Tayade HP, Jaju JB, Mateenuddin M (2003). Effect of aqueous extract of Azadirachta indica leaves on hepatotoxicity induced by antitubercular drugs in rats. Indian Journal of Pharmacology, 35: 177-180.

Koona S, Budida S (2011). Antibacterial Potential of the Extracts of the Leaves of Azadirachta indica Linn. Notulae Scientia Biologicae, 3: 65-69.

Lamberg SL, Rothstein R (1978). Laboratory Manual of Hematology and Urinalysis. Avi. Publishing Company, Inc, West Port Connecticut, USSR.

Landy N, Ghalamkari GH, Toghyani M (2011). Performance, carcass characteristics, and immunity in broiler chickens fed dietary Neem (Azadirachta indica) as alternative for an antibiotic growth promoter. Livestock Science, 142: 305-309.

Mishra A, Mamta, Neema, Niketa, Poonam, Pranjul, Priyanka (2013). Antibacterial effects of crude extract of Azadirachta indica against Escherichia coli and Staphylococcus aureus. International Journal of Science, Environment and Technology, 2: 989-993.

Molla MR, Rahman MM, Akter F, Mostofa M (2012). Effects of Nishyinda, black pepper and cinnamon extract as growth promoter in broilers. The Bangladesh Veterinarian, 29: 69 - 77.

Nayaka HBS, Umakantha B, Ruban SW, Murthy HNN, Narayanaswamy HD (2013). Performance and hematological parameters of broilers fed Neem, turmeric, vitamin e and their combinations. Emirates J ournal of Food and Agriculture, 25: 483-488.

Nayaka HBS, Umakantha B, Ruban SW, Murthy HNN, Narayanaswamy HD (2012). Effect of Neem, Turmeric, Vitamin E and Their Combinations on Immune Response in Broilers. Global Veterinaria, 9: 486-489.

Thakurta P, Bhowmik P, Mukherjee S, Hajra TK, Patra A, Bag PK (2007). Antibacterial, antisecretory and antihemorrhagic activity of Azadirachta indica used to treat cholera and diarrhea in India. Journal of Ethnopharmacology, 111: 607-612.

Westergren A (1957). Diagnostic tests: the erythrocyte sedimentation rate range and limitations of the technique. Triangle, 3: 20-25. 